\title{
Who watches YOU? An allegory of dataveillance and cyberstalking
}

\author{
Luiz Paulo Carvalho ${ }^{1}$, Jonice Oliveira ${ }^{1}$, Flávia Santoro ${ }^{2}$ \\ ${ }^{1}$ Programa de Pós-Graduação em Informática - Universidade Federal do Rio de Janeiro (UFRJ) \\ Rio de Janeiro - RJ - Brasil \\ ${ }^{2}$ Dep. de Ciência da Computação - Universidade do Estado do Rio de Janeiro (UERJ) \\ Rio de Janeiro - RJ - Brasil \\ luiz.paulo.carvalho@ppgi.ufrj.br, jonice@dcc.ufrj.br, \\ flaviamariasantoro@gmail.com
}

\begin{abstract}
How your openly published personal data in Online Social Networks are used by other people? Not only organizations and companies are interested in them. From a qualitative approach, we present a hermeneutic of an episode of the TV series YOU, building an allegory that exposes the potential for cyberstalking and dataveillance. The romanticization and naturalization of these phenomena is tensioned, they are based on ethically dubious intentions and a semiotic discourse harmful to social sustainability.
\end{abstract}

\section{Introduction}

As a child, many of us heard from our parents, or guardians "don't talk to strangers". The purpose of this lesson is case-based, with me it was not just a concern for my safety, as a naive and inconsequential child, also because I had the potential to provide information that would endanger the rest of those close to me. A person could try to collect data such as where I lived, my parents' names, where I studied, how much my father earned, whether I had a dog or not, if and when we would travel, as many others. And that interested party could, based on this data, decide how risky it was the cost-benefit of an action. If it is a poor family, is it worth stealing from them? Since they are going to travel, is this the best opportunity? If you have a dog, it is dangerous? By the parents' surname, is it a wealthy family? These are your personal data. They are indirectly related to other people's data, who did not consent or had a notion of this exposure.

Imagine if you publicly and constantly offer compromising information on the Internet. And you should not be acting like a naive and inconsequential child, not anymore. But you don't offer them explicitly, your uniform exposes the school where you study and possible location; your meals show your eating habits and can suggest your social class, just as your dog's breed can expose your social class too; the geolocation exposed in the photos that you identify as "I'm at home"; photos of your home and what are in it expose a lot about your life; if you are traveling, to find out if your home is empty, including where you travel to also suggests your social class. Neither you nor I expose our personal data ${ }^{+}$, publicly or otherwise, hoping that it will be used for a purpose that will harm us, not necessarily in a physical way, or negatively unexpected.

\footnotetext{
${ }^{+}$In this work we use personal data and personal information as synonyms. When a data receives a meaning, through a semantic association, it becomes information [STAIR AND REYNOLDS, 2018].
} 
The number of users in Online Social Networks (OSN) is increasing, in Brazil and worldwide ${ }^{1}$. Worldwide, Facebook alone has more than two billion users, yet in Brazil, YouTube was the most used social network of 2019. The largest number of OSN users are post-adolescent (18-24) and young adults (24-35), not all of whom had an effective digital literacy or digital nativity [PRENSKY, 2001] [MANZOOR, 2018], for example, alienated from the notion of reach and consumption that their personal data treatment may result, in the medium or long term.

The misuse of personal data by public and private organizations has already been broadly studied [BIONI, 2019]. Influenced by this phenomenon, countries have regulated and passed their legislation for privacy and data protection. Like Brazil, under the General Data Protection Law (Lei Geral de Proteção de Dados - LGPD) [BRASIL, 2018] and the European Union, under the General Data Protection Regulation (GDPR) [EU, 2016], in force over all the countries in the bloc.

The mandatory determination for school curricula in the Brazilian Basic Education Curriculum, approved and updated in 2017, contains specific items to instruct and develop students aware of their OSN relationships, involving personal data [BRASIL, 2017]. The Brazilian Computer Society (Sociedade Brasileira de Computação - SBC) is an organization committed to the inclusion of computer education in the Brazilian Basic Education curriculum, also having an exclusive board for this purpose [SBC, 2019].

Processing $\Omega$, in a broad sense, of personal data by other individuals, for private and non-commercial purposes, is not a simple phenomenon to be analyzed, constituting a gray area in the legal and social debate. Extreme cases, such as proven unauthorized disclosure of nudity, as revenge pornography, are well located on the ethical and moral scale of society [VASCONCELOS et al., 2019], but many others are not.

As we are dealing with societal concrete cases, we can present real examples: the citizen, with good intentions, who collected resumes in the trash and helped their owners to find jobs ${ }^{2}$; the daily cleaner who used her contractor's Facebook photos as proof of her financial condition '3; the online stalkscan system, which uses Facebook's open data (which users have configured as public) to build profiles and extract data about specific users ${ }^{4}$. We were unable to access stalkscan, although a brief search exposed similar solutions available. Irresponsibly and with examples, which can serve as instructions for malicious stakeholders, the media report on the misuse of personal data ${ }^{5,6}$.

One of the ethical-moral dubious uses of personal data is supposedly "tracking" someone else. This activity is known as stalking, when restricted to the physical scope, or cyberstalking, when it also involves the digital scope. Unlike researching or collecting extensive data about someone, stalking involves chasing and interacting with the target, presenting a pattern of repeated and unwanted contacts that are experienced as intrusive by the target, leading to distress or fear [MULLEN et al., 2001].

Stalking is a behavior associated with personality disorders, such as psychopathy

\footnotetext{
${ }^{1}$ Due to the recommended depth for conducting a contemporary and updated qualitative research [BHATTACHERJEE, 2012], a lot of informal, non-scientific, and pop culture content will be cited in abundance, such as interviews and reviews. The footnotes are strictly listed in an online and open file, in order not to pollute this reading. Available at: encurtador.com.br/wDEV5. Accessed on: 03/30/2020.

$\Omega$ Activities related, but not restricted, to the collection, production, reception, classification, use, access, reproduction, transmission, distribution, processing, archiving, storage, elimination, evaluation or control of information, modification, communication, transfer, dissemination or extraction [BRASIL, 2018].
} 
and sociopathy, configuring a mental disorder [MCKEON, 2015]. Despite the tension presented here, we need to reinforce stalking as a socio-culturally negative practice; its followers or supporters need treatment, proportional to their leaning for this practice.

The insertion and processing of personal data are a risk sociocultural activity. When a user consciously enters and configures data as public, like geolocation or personal photo, he no longer controls, at that time and domain, that data. How this legitimate disclosure intention works? Excluding the freedom of image or expression and informational self-determination [BIONI, 2019], how does this user imagine that his personal data will be processed by others? Ethically? As data freely externalized on the Internet, what is the reach expectation? What if it is Another country? Or used by someone malicious? How will it sound five years from now? As exposed at the beginning, we no longer need to avoid communicating with "strangers", as it was recommended to children, because now data about us is publicly and openly available on the digital network. We no longer need "talking to strangers", because we have already provided all, or much, of the information he needs.

The abundance of data available in digital networks facilitates the pursuit and monitoring of targets in stalking practices. Realizing with conviction that your data is being monitore is not trivial, especially for laypeople. "God's eye view" is the denotation for traditional surveillance [MANN, 2004]. Data-based vigilance would be close to a mystical "foggy crystal ball", without constant inputs, precision, or certainty, different from a camera capturing everything and everyone, explicitly. For the category of sight (from the French word veillance) using data, the name Dataveillance is assigned.

There is a growing personal data influence on societies and, as a focus of this work, interindividual relations. We present, from a qualitative interpretative methodology, a hermeneutic allegory analyzing the consequences of self-exposure of personal data in the OSN instantiated in the television (TV) series YOU, specifically the first episode from the first season. The transdisciplinary bias involves disciplines such as Informatics, Law Studies, Gender Studies, Psychology, Ethics, and Communication.

The work is structured as follows, Section 2 presents explanations about the work to be analyzed; Section 3 presents the methodology, detailing the epistemology of allegorical hermeneutics; Section 4, contributions and transdisciplinary analyzes, emphasized in Informatics; section 5 ends with the discussion and conclusion.

\section{Who does watch YOU? \#}

In this Section the object of the research will be detailed, the first episode of the first season of the TV series YOU; relevant externalist notes on the author, Caroline Kepnes.

\section{1 "Pilot"}

The TV series YOU, released in 2018, was inspired by the eponymous book, released in 2014, by author Caroline Kepnes ${ }^{8}$. The series was originally available on the Lifetime channel, it was only after its purchase that Netflix made it popular ${ }^{8}$. The criticism is positive, both in the Internet Movies Database (IMDb) website, scoring an 8.3/10

\footnotetext{
\# This title is a play with the Latin expression "Quis custodiet ipsos custodes?". One of its translations being the famous phrase "Who watch the watchers?". Used, in its original context, for marital fidelity, it was later appropriate for surveillance by pop culture ${ }^{7}$.
} 
evaluation ${ }^{9}$, and in the review aggregator website Rotten Tomatoes, with $90 \%$ public approval ${ }^{10}$. The first season was watched by more than forty million people ${ }^{8}$.

In this work we examine the first episode of the first season, named "Pilot". Eventually, if necessary, we will address brief points from other episodes. The allegorical analysis of the work will be punctually, so we will not build a synopsis. For contextual immersion, we recommend that the reader also watch and follow us in this work.

To introduce, a synopsis from Rotten Tomatoes: "Joe meets Beck, falls in love and goes down a social media rabbit hole to learn everything about her. He becomes so obsessed that he tracks her IRL (and they meet again). This might be a real shot at real love. But there are some things standing in the way... like her ex, Benji." ${ }^{10}$. They present a synopsis for the entire series, first and second seasons so far: "A tech-savvy young man utilizes modern-day resources to lure a woman into falling in love with him." 10.

\subsection{The author, Caroline Kepnes}

Caroline Kepnes graduated from Brown University, concentrated in the area of American Civilizations. In this way, she managed to unite his love for writing and psychology ${ }^{11}$.

Her perception of the main character, Joe, is related to love, not a mental disorder. Kepnes defines Joe as someone who "wants love" ${ }^{12}$. In many interviews, reviews, opinions or content produced about the series, Joe is defined as "dense", "chivalrous", "romantic in his own way"; Beck is defined as "shallow", "basic" or even "needy" 16. And the author endorses this impression, reinforced by the imagery of the episode's discourse. This is how Beck is conceived and represented, as a dependent, messy, and disorganized; while Joe is focused, methodical, and rational.

One of the common resources of writers is to build characters in their image, mirrored in themselves. Usually, these will be the protagonists or main characters of the works. Unusually, the character that the author built based on herself was Beck, not Joe ${ }^{13}$. The same strongly reinforces that Joe was not based on her ${ }^{12}$.

"I liked this idea of Joe just being a prince who takes it too far. While I was writing, I never thought of him as a serial killer [...]", said Kepnes ${ }^{13}$. In this sense, it is important to deepen also in the authors. In Informatics, certain software analyzes need to extrapolate the artifact in question and overflow to the parties involved in its design, as software developers [REZVANI AND KHOSRAVI, 2019]. Several features of those involved in the construction of an artifact, which may be a software or a literary work, are imported into it, its history, its values, its ideals, its personality, among others. It is not surprising that Joe's presentation is not as a villain, but as a "romantic who crosses the line" 12 .

From the beginning to the end of the season, Joe commits heinous and unethical acts and gets away with them. Symbolically, this discourse indirectly represents the idea of a character with a mental disorder, with Joe's profile, to act illegally and succeed in his plans. The author, then, reinforces a dubious morality in her conclusive message, as an example of negative attitudes (cyberstalking) on the one hand, on the other hand as a symbolic example that you can act in bad faith that will do well in the end, without consequences, because you are "extraordinary and well-intentioned" (invades the privacy of others through uncontrolled passion, which is the victim's fault for awakening). 


\section{Methodology and research approach}

Hermeneutics [CHALMERS, 2004] [MINGERS, 2001] is the qualitative methodology approach of this work. Dedicated to the theorization and methodology of discourse interpretation, also audio-visual and its material symbolisms, such as semiotics [MYERS, 2015]. It is suitable for interpretive research [BHATTACHERJEE, 2012].

Hermeneutics provides a way to understand how socially constructed systems of meaning become accepted (legitimate) or challenged, sees prejudice, biases, and prior knowledge as essential, presenting inter-subjective findings, distancing from the objectivist and subjectivist dualism. The contemporary and material analysis of the intersubjectivities that permeate society with the abstract or concrete forces influencing them do not let us alienate the composite objects, such as laws, traditions, customs, curricula, and others [MYERS, 2015]. Hermeneutic analysis must consider its broad context and associate it to a certain space and time and cannot ignore them [BARRETT et al., 2011].

Two combinations of Hermeneutics lines are present, Critical Hermeneutics and Depth Hermeneutics [MYERS, 2004]. In the critical aspect, human communication takes place through political and socio-cultural constraints, involving the reduction of illusions and the restoration of meanings, while the depth aspect involves a deep meaning, which is not on the surface of the "text" and which tensions the author's conscious and subconscious. In Section 2.2 we have tensioned Joe's pseudoromantic category.

From a semiotic perspective [BHATTACHERJEE, 2012], we analyze the symbolic elements as an allegory that represents the unexpected, instrumental, and ethically dubious use of personal data in contemporary society in the early 2020s. Joe Goldberg, the main character, operationalizes insistent strategies from data surveillance and social engineering to "conquer" the character in which he becomes obsessed, the graduate student Beck, exposing a morally questionable cyberstalking and stalking case.

Joe's behavior can be figuratively associated with how organizations treat our personal data, however on a much larger scale, using complex technological devices, such as Artificial Intelligence (AI). The key criterion is scalability. The research challenge is to build the associative interpretation between the allegory and the real context, involving transdisciplinary data-driven applications, with consent or not.

All the principles proposed by Bhattacherjee (2012) for qualitative scientific research are followed: (a) Naturalistic Inquiry, achieved by instrumentalizing content built on the object of the research, the informality of communication in pop culture and the formality of scientific rigor; (b) Researcher as an instrument, where we position ourselves and build the research properly and characteristically, positioning ourselves; (c) Interpretive analysis, understanding the subjective perspective of the work and analyzing meanings and narratives of interest; (d) Use of expressive language, not limited to what is explicit, here we propose an allegory as an implicit contribution; (e) Temporal nature, contextualizing the research in the time and space proposed and duly deepened by the researcher; (f) Hermeneutic circles, iterating the process between the observed research object and the social phenomenon, reconciling the apparent disagreement and theorizing from it through "theoretical saturation" of the plural knowledge available. 


\section{A hermeneutic analysis}

In this section, we will present a hermeneutic associating the technological implication of the culture of "open" data processing for morally questionable purposes with applicable scientific theories and related content.

\subsection{It is not just about the virtual scope}

The episode starts with Beck going to the bookstore to buy some books. Just by going through the door of that restricted domain, Joe starts profiling. Profiling is a process that uses personal data as an input and provides a profile as an output, which can be calibrated according to specific parameters and stereotypes, such as socio-cultural [BIONI, 2019].

Profiling is not, a priori, an immoral or unethical practice. The reality external to us is cognitively represented through mental models, used to anticipate events, reason, and form explanations [JONES et al., 2011]. We all carry small models of how the world works within us [CRAIK, 1967]. Semiotically, internally we assign inferential roles through publicly available symbols or mental representations, which are historical, cultural, and individually specific [CAREY, 2015].

It is, then, natural that Joe profiled Beck and built a mental model of her. From observation and internal specific skewed stereotypes, he begins to profile her. At no time does he validate any inference or actively ask for her personal data. It infers that she is a student; its possible literary consumption practices from it; a "nymph" 14, that is, beautiful, young and graceful; and lacking attention, reinforcing a misogynistic bias ${ }^{15}$.

His interest in her is intensified and consolidated when Beck interacts directly with him, asking for assistance. It reaches the point where Joe realizes intrusively that Beck is without a bra, thinking that it is specifically for him to notice. Just because Joe spotted money and she preferred to pay by card, Joe guesses that it is because she wants him to know her name, identify her. He mentally concluded: "You smile, laughed at my jokes, told me your name, asked for mine.". She was just being polite and friendly, only asked his name because he interacted with her name registered in the credit card.

It is from this moment that Joe becomes obsessed and begins to stalk her. Then there is a shift from internal symbolic interest to concrete, externalized interest.

\subsection{Stalking and Cyberstalking}

Another bookstore employee, Ethan, teases Joe when Beck leaves. Ethan is then the first to reinforce Joe's interpretation that Beck was interested in him and amends, roughly, recommending that Joe find Beck on the Internet, "I'd be googling the hell out of her right now. You know her full name". Ethan's passable "innocence" or "dim-wit" is debated in texts over the Internet ${ }^{16}$. Which is inconsistent, since he is the first to push Joe towards Beck, fueling the obsession and encouraging him to cyberstalk her.

Going home, lost in thought, Joe rescues memories of the last relationship, showing the beginning of his mental disorder by behavioral surveillance, "I should have seen the signs. But we never do when we're in love". At this moment, the episteme of Joe's logic until the end of the season is presented. He needs to "see the signs". He needs to prevent himself, to anticipate, to control the situation. As he points out, "protect himself". Therefore, he needs data, as much personal data as possible, so he can then decide if she is "satisfactory enough for him", and not a new disappointment. 
At this moment, the profiling intensifies. Joe quickly finds Beck among the few Guinevere Beck found in his research, then starts to amend one social network to another, in what appears to be the Facebook, Twitter, Tumblr, and Instagram interfaces. Dig out all searchable information about her. Since her social networks are set up as public, open, and allowed to be found by search engines, it makes Joe think that Beck "wants to be seen, heard and known", reassuring the "attention whore" label.

The abundance of available personal data of Beck helped Joe to infer about her personality [AGRESTI, 2018]. He begins to stalk Beck, physically now. By watching her at the university, he observes that her mentor touches Beck's back with a certain intimacy. So, he infers that he has sexual intentions towards Beck, and she feeds this intention to keep her research grant, "Professor obvious wants to fuck you. Now you're smart. You let him think one day he might". Any data that Joe is unable to collect instigate him to further pursue, to obtain more data, and build a more consistent profile, even if it means invading her privacy and resorting to private and restricted data.

Joe uses the full potential of data analysis [AGRESTI, 2018] to profile Beck. He finds out that she spent her childhood on Nantucket; the brothers' profiles and who they are; which graduation and university she attended; work address; time at work; how old she was when her parents divorced; purpose to move to New York; her friends; and others.

Cyberstalking is stalking employing email, text (or online) messages, or the internet [EIGE, 2017]. Stalking is broadly defined as a pattern of repeated and unwanted contacts that are experienced as intrusive by the recipient and lead them to feel distressed or fearful. The reactions of the targets, experienced as victims, that identifies when stalking happened, not the perpetrator intentions [MULLEN et al., 2001], bringing the debate even closer to the interpretive field. There is a media romanticization built around the culture of stalking and the characters who practice it [LIPPMAN, 2015], which is reinforced in YOU, as explained in Section 2.2. People reinforce that the victim was the one who was provoking; categorize the stalker's behavior as romantic; or that you need to have physical violence to set up a stalking case [MCKEON, 2015].

The behavior of using someone else's personal data, coming from social networks to stalk, monitor, and act respectively, even if only in the virtual scope, constitutes stalking. This concern is urgent to demystify the "virtual" $\times$ "real" dichotomy that affects cases of violence against women, who are the biggest victims of this practice ${ }^{17,21}$.

Strictly in the digital scope, Joe's attitude cannot be defined as strictly unethical. Searching data configured as open and public on the Internet is not a malicious act, even if it is personal data. If we consider the legislation [BRASIL, 2018], data configured as public by their owners are not included in the generic and abstract scope of data protection. Bioni (2019) argues that in this case, it is necessary to analyze the ultimate nature of the platform on which the data was made available, for example, on Facebook, it is, in his words, "to relate to those who are part of their social circle". Nevertheless, if all your profile settings and data are set to public, does not that mean you want to be "seen, heard and known" by others? Others who want to integrate and participate in your social circle? In that case, we can consider an information security problem.

\subsection{Information Security aspect}

Joe performs several Information Security illegalities to obtain more personal data about Beck, not directly associated with her. For more data, Joe commits many crimes 
related to information security [ANDRESS, 2019], and only in one episode.

Applying Social Engineering techniques, get advantage from a breach in the law and social relationship stereotypes to break into Beck's residence, to physically access their intimacy, and virtually access their data, through the available devices; Evil maid attack, utilizing devices, that do not have access security measures as password, kept in Beck's private environment of his home; Eavesdropping, constantly following and listening, or trying to, his conversations, in disguise; Hardware theft, when she is drunk and vulnerable steals her phone. He intends to keep the device running while Beck acquires a new one, using the data pairing of them. The cell phone, too, is not password protected; False identity, uses a fake account in a social network to imply that he is someone else to lure Benji, Beck's ex-boyfriend, into an ambush because he believes Benji is a threat to his romantic strategy. After kidnapping him, in the next episode, there is a change of interest. It is a valuable source of Beck's intimate and relational information, and Joe explores this until he murders Benji later.

One of the worst dilemmas in this context is presented, privacy versus security. If possible, we ask that you watch the scene with the criticism presented here, right after the thirty-third minute. Joe on the subway platform waiting for the train to arrive, disenchanted by Beck "humbling" herself passionate for his ex-boyfriend, which is a healthy human behavior and her right. Beck arrives, drunk and unbalanced, and fiddles with her cell phone, ignoring the safety strip, on the verge of falling. Joe hides behind a pillar. Unsurprisingly, Beck falls on the subway tracks. Joe then rescues her, not only pulling her at the last second before the train hits her, but also alerting her immediately after the fall that she can die electrocuted if touches the tracks.

Two questions emerge (i) why doesn't Joe help Beck in this moment of frailty in need of help? (ii) if Joe wasn't stalking Beck (hiding inside her apartment when he found out where she was going) there would be no chance that he would be close to her in a moment of fragility like this and she would die, how the scene conducts and suggests. So, Joe's stalking outweighs his initiative to subtract Beck's privacy?

Tensions associate Ethics, Privacy, and Security in the Informatics field [BARRETT-MAITLAND AND LYNCH, 2020] [BASHIR AND KHALIQUE, 2016]. What is the limit, or if there is one, of privacy and ethics when it comes to security? An example, during the COVID-19 outbreak, which of these should be a priority ${ }^{18,22,23}$ ?

Even so, many viewers expressed attraction or romantic interest in Joe, and the actor who plays him tried to answer these messages by clarifying that Joe is a murderer and a bad person ${ }^{17}$. A possible justification is the connotation that he goes to the limit for her, not against her; it does not harm her, but "for" her. All of Joe's effort is not to alienate her, but to take the reins of his right to personal identity [MARSHALL, 2014].

\subsection{How much can you manipulate someone's personality?}

The right to personal identity does not have a clear and consensual concept [MARSHALL, 2014], it constitutes an unfinished, transitive, and cultivable notion [MARTINS-COSTA, 2003]. We can interpret it as being composed of elements such as name, image, honor, physical integrity, among others [BIONI, 2019].

Joe constantly shows an intention to "make Beck a better person" or "make her life better", saying that he will cook for her, take care of her books, set passwords on his 
devices, or even "improve" his friendships. Beck does not ask for it, not even figuratively.

There is a Joe's psychopathic intention to grow in Beck, intrinsically, the feeling of attraction for him, without her consent or perception. Constituting something theatrical, from all the data collected about her, He can simulate in himself the "best and most compatible" personality that leads Beck to be attracted and interested, and thus become the "perfect choice", even if spontaneously it is not a legitimate choice at all.

This approach is similar to "seductive" algorithms that capture our attention, using captivity metrics that are opaque to the user [SEAVER, 2018]; and with targeted marketing, a modality aimed at a group of potential targets who will consume the product or service in question, preferably masking that the advertising message is a consumer appeal, leading the consumer to believe that, spontaneously, acquired something that met his needs [BIONI, 2019]. This need may also have been fed artificially.

All this effort to understand and delve into Beck makes it seem like Joe is in healthily love, thinking about her well-being, almost in a gentlemanly way.

\section{5. "Chivalry", identities, and gender discrimination}

Lippman (2015) deals with how the media, like YOU, exposes stalking, contextualized in feminism, and analyzed through a socio-cognitive bias. When an explicit and clear violence discourse against the victim recipients are less adherent to the stalking myths, e.g., is a romantic behavior. Conversely, exposure to romanticized persistent pursuit led to increased endorsement of stalking myths.

We need to go back to Kepnes; she builds Joe as a "classic gentleman". We realized this in two moments, and they are important for interpreting the ill-minded paternalistic and supervisory behavior. Don Quixote is a literary character commonly analyzed as a case study for several mental disorders [SUDOL, 2016]. And Joe uses him as an example during a scene teaching a child, where the same question asks what chivalry is and he replies, "It's treating people with respect, especially women ... like men should". In another moment Joe exposes, "The most valuable things in life are usually the most helpless. So, they need people like us to protect them".

As in the pop culture novel Twilight ${ }^{19}$, in which the main female character Bella Swan is categorized as an anti-feminism case [EDDO-LODGE, 2013], Beck is represented with several negative attributes and developed in such a way that her subjectivity and life choices are detrimental to herself, leading to think that she needs something that "helps her" and "cleans the bad things in her life", as Joe says.

Internet users commented on the identity privileges of Joe's representation on the TV series. Being white, beautiful, thin, polite, well-intentioned, and heteronormative ${ }^{16}$,

${ }^{20}$ it is easier to have advantages in the macro socio-cultural context of the series and more than that, to become a desirable character for the audience. Identity discrimination based on the personal data processing is an Informatic hot topic, there is no algorithm without bias or detached from the material reality of action [SUMPTER, 2018]. How to build artifacts, algorithms, or TV series characters, that do not harm social sustainability?

\section{Conclusion}

With a qualitative interpretative bias, we present in this work a hermeneutics of the episode "Pilot" from the TV series YOU, with a transdisciplinary approach and focus on 
Informatics, building an allegory for the predatory use of personal data. Our contributions are a technological hermeneutics exposing a particular and ethically dubious use of personal data; an allegory that can be used as an object of teaching digital literacy and cyber ethics; an instance of processing public and open personal data on social networks that violate the principles in good faith, taking advantage of loopholes in the law.

This allegory can (and should) be extrapolated, with due contextual care, to an association in which Joe operates as a data-driven system, be it a platform or an algorithm, how we try to sew throughout Section 4. After interpreting that the user (Beck) was interested in something that the system (Joe) could offer, such as protection or a "better life", it begins to use all his reach and power to collect as much personal data about the user as possible, to build the most complete profile and make the decision whether he "is worth it or not" to be a target of the system's effort and resources. If it is, the goal will then be to find a way to make him believe that needs the system's services and products, indirectly and subconsciously. To this end, stereotypes and socially biased data are used, effective concerning an individual of the respective extract from the specific population. With the "well-intentioned" subterfuge of "improving" user's life, it invades his privacy, even though any sort of possible questionable ethical act, to improve his decision-making.

Invasively and without consent, the system is not restricted to its users, can also involve people near them, profile them and interact, recommending things (even if they are not in the system, a practice called "shadowing" [GARCIA, 2017]).

In this way, we can also use the hermeneutic of this work to exemplify the direct or indirect dangers of exposing personal data openly and unrestrictedly in a medium of as much reach as the Internet. If Joe had not found any personal information about Beck, would he have been interested in her? Would he still be able to accurately discover where she lives, works, and studies? Would the possible cross-data that he would find about her in the profile of others (through shadowing), be enough? In our interpretation, no. Beck is deliberately and purposefully constructed by Kepnes as (i) or, in fact, someone who "wants to be seen, heard and known", optionally naive of the potential personal data use; (ii) or digitally illiterate, cognitively vulnerable as a user of social networks. Joe, as the second episode shows, has no social network, having a perception of the possible prey $\times$ predator data-based scenario.

At the same time, we reinforce that at no point in time Beck is guilty, she is the victim. And while Kepnes does not explore Joe's mental diagnosis throughout the episode and entire season, he does exhibit all the concrete behaviors of serious mental disorder, dangerous to society. So even if Joe had received the best possible education on digital literacy and ethics, the onus would still be on Beck, because his mental condition would prevent him to differ "right" and "wrong", "ethical" and "unethical", "intimacy" and "openness". Honestly, Joe needs proper attention and treatment. Even in the hypothetical universe with excellent ethical digital literacy, "Joes" are possible.

In conclusion, we are responsible for our personal data and, in personal scope, for its possible reach. Whether to protect your data from organizations, as regulated by the LGPD; awareness and education, such as the BNCC guidelines; or cyberstalkers, as the interpretation of this work exposes. As future works, we can list the analysis of other episodes in the series; technological deepening at a logical or physical level; construction of new, well-founded hermeneutics; and a look dedicated to specific characters or events in the series, not episodes. 


\section{References}

Agresti, A. (2018) "An Introduction to Categorical Data Analysis". 3rd ed. WILEY. ISBN: 978-1-119-40526-9

Andress, J. (2019) "Foundations of Information Security: A Straightforward Introduction". USA, No Starch Press.

Barrett, F., Powley, E., Pearce, B. (2011) "Hermeneutic philosophy and organizational theory". Research in the Sociology of Organizations. DOI: 10.1108/S0733$558 X(2011) 0000032009$

Barrett-Maitland, N., Lynch, J. (2020) "Social Media, Ethics and the Privacy Paradox". IntechOpen. DOI: 10.5772/intechopen.90906

Bashir, B., Khalique, A. (2016) "A Review on Security versus Ethics". IJCA. DOI: 10.5120/ijca2016911937

Bhattacherjee, A. (2012) "Social Science Research: Principles, Methods, and Practices". Textbooks Collection. 3. USA, Global Text Project.

Bioni, B. (2019) "Proteção de Dados Pessoais - A Função e os Limites do Consentimento". ed. 2, Forense. ISBN: 978-8530988623.

Brasil (2018) “LEI No 13.709, DE 14 DE AGOSTO DE 2018”. Lei Geral de Proteção de Dados. Disponível em: http://bit.ly/2YgUqMZ

Brasil, Ministério da Educação (2017) "Base Nacional Comum Curricular". Available at: http://basenacionalcomum.mec.gov.br/. Accessed in: 03/30/2020.

Carey, S. (2015) "The science of cognitive science". Social Anthropology/Anthropologie Sociale. DOI: $10.1111 / 1469-8676.12119$

Chalmers, M. (2004) "Hermeneutics, information and representation" European Journal of Information Systems. DOI: 10.1057/palgrave.ejis.3000504

Craik, K. (1967) "The Nature of Explanation". Cambridge University Press. ISBN: 9780521094450

EIGE - The European Institute for Gender Equality (2017) "Cyber violence against women and girls". DOI:10.2839/876816

EU - European Union (2016) "General Data Protection Regulation (GDPR): Regulation (EU) 2016/679". Available in: https://gdpr-info.eu/. Accessed in: 03/30/2020.

Eddo-Lodge, R. (2013) "The Anti-Feminist Character of Bella Swan, or Why the Twilight Saga is Regressive". Kriticos, v. 10. ISSN: $1552-5112$

Garcia, D. (2017) "Leaking privacy and shadow profiles in online social networks". Science Advances. DOI: 10.1126/sciadv.1701172

Jones, N. A., Ross, H., Lynam, T., Perez, P., Leitch, A. (2011) "Mental models: an interdisciplinary synthesis of theory and methods". Ecology and Society 16(1): 46.

Lippman, J. (2015) "I Did It Because I Never Stopped Loving You: The Effects of Media Portrayals of Persistent Pursuit on Beliefs About Stalking". Communication Research. DOI: $10.1177 / 0093650215570653$

Mann, S. (2004) "Sousveillance: inverse surveillance in multimedia imaging". Proceedings of the 12th ACM ICM. DOI: 10.1145/1027527.1027673 
Manzoor, A. (2018) "Media Literacy in the Digital Age: Literacy Projects and Organizations. In Information and Technology Literacy: Concepts, Methodologies, Tools, and Applications". IGI Global. DOI: 10.4018/978-1-5225-3417-4

Marshall, J. (2014) "Human Rights Law and Personal Identity: An Introduction" University of Leicester School of Law Research Paper No. 14-30. Available at SSRN: https://ssrn.com/abstract $=2521117$

Martins-Costa, J. (2003) "Pessoa, personalidade, dignidade: ensaio de uma qualificação". Tese (Livre-docência). Faculdade de Direito da Universidade de São Paulo. São Paulo, 2003. p. 233

McKeon, B., McEwan, T., Luebbers, S. (2015) "“It's Not Really Stalking If You Know the Person": Measuring Community Attitudes That Normalize, Justify and Minimise Stalking". Psychiatry, Psychology and Law. DOI: 10.1080/13218719.2014.945637

Mingers, J. (2001) "Combining IS research methods: Towards a pluralist methodology". Information Systems Research. DOI: 10.1287/isre.12.3.240.9709

Mullen, P. E., Pathé, M., Purcell, R. (2001) "Stalking: new constructions of human behaviour". Australian and New Zealand Journal of Psychiatry. DOI: 10.1046/j.14401614.2001.00849.x

Myers, M. D. (2004) "Hermeneutics in information systems research". In Social Theory and Philosophy for Information Systems, org. Mingers, J., Willcocks, L., pp. 103-128. John Wiley \& Sons. ISBN: 978-0470851173

Myers, M. D. (2015) "Hermeneutics in organization studies". The Routledge Companion to Philosophy in Organization Studies. DOI: 10.4324/9780203795248.ch7

Prensky, M. (2001) "Digital Natives, Digital Immigrants Part 1". On the Horizon. DOI:10.1108/10748120110424816

Rezavni, A., Khosravi, P. (2019) "Emotional intelligence: The key to mitigating stress and fostering trust among software developers working on information system projects". IJInfoMag. DOI: 10.1016/j.jinfomgt.2019.02.007

SBC - Sociedade Brasileira de Computação (2019) "Computação na Educação Básica". Computação Brasil, no 41. SBC, Porto Alegre.

Seaver, N. (2018) "Captivating algorithms: Recommender systems as traps". Journal of Material Culture. DOI: 10.1177/1359183518820366

Sudol, I. (2016) "Psychological Pathology and Aging in Cervantes's Don Quixote de La Mancha". Hispanic Studies Honors Papers. 3.

Sumpter, D. (2018) "Outnumbered: From Facebook and Google to Fake News and Filterbubbles - The Algorithms That Control Our Lives". Bloomsbury Sigma. ISBN: 9781472947413.

Vasconcelos, P., Gomes, B., Vargas, R. (2019) "O AMPARO JUDICIAL E PSICOLÓGICO AS VÍTIMAS (MULHERES) DA PORNOGRAFIA DE VINGANÇA E A INSTITUIÇÃO DA LEI 13.718/2018". Revista Transformar, 13(2). E-ISSN:2175-8255. 